\title{
Crimes against Benefits of Organs in Fiqh and Penal System of Iran
}

\author{
Jamal Asayeshi $^{1} \&$ Khalil Afandak ${ }^{2}$ \\ ${ }^{1}$ Department of Law, Ardabil Branch, Islamic Azad University, Ardabil, Iran \\ ${ }^{2}$ Department of Law, Ahar Branch, Islamic Azad University, Ahar, Iran \\ Correspondence: Jamal Asayeshi, Department of Law, Ardabil Branch, Islamic Azad University, Ardabil, Iran. \\ E-mail: Asaueshi@gmail.com
}

Received: June 6, 2016 Accepted: July 6, 2016 Online Published: July 31, 2016

doi:10.5539/jpl.v9n6p9 URL: http://dx.doi.org/10.5539/jpl.v9n6p9

\begin{abstract}
Benefits of organs refer to non-material forces put by God in human organs definite or indefinitely e.g. eyesight in the eyes, wisdom in brain, or heart beating. The benefits of internal organs are like the organs outside the body and is under cover of the general rule of whatever there is only one of it in the body, the blood money will be a full one. Many scholars have mentioned the obligation for a full compensation for destruction of each organ. Several studies have been conducted on the elimination of benefits or determination of the value of the organ in religious regulatory books and their evaluation in Islamic jurisdiction and Islamic penal code. This penalty is sometimes called blood money or in other cases compensation. This money is determined by religious codes and should be paid by the criminal for compensating the damage induced by him. Elaboration on these benefits in religious books and then discussing the rules and regulations and finally comparing them with Iranian legal system is the goal followed by the author of the present work.
\end{abstract}

Keywords: crime, organs, compensation, Fiqh and law, body

\section{Introduction}

Law is the science of human social life rights. In recent centuries people have been trying to create rules and regulations in their social life and group in the form of social contract to this order and price. Among these elements of the distant past and the arrival of modern life, it creates a new look and changes in the field of social and legal issues. Diyah (blood money) is also one of the same topics. Review and accuracy in the history of human civilizations and various ethnic group represents this entry is that of Johnny's compensation as punishment or compensation has a long history dating back to the long life of mankind. This process little by little with the passage of time and the arrival of new components and elements, entered a new stage. In Islam the official religion, the Islamic Republic of Iran, and stressed this issue explicitly was accepted and this indicates that the signature of a child of Islam is in fact in order to create peace and harmony among the families and tribes and was approved by Islam.

Man is composed of two dimensions is composed of soul and body, which should both protect and satisfy the needs of both, as the context of its growth and development. Health is not merely the appearance of the object but also the protection of human right in the path of his members to balance each of their usual duties and interests the objective of realizing them. Although many interests or are not taken into consideration or not achieved human knowledge to them. Maintain health or compensation for injuries incurred by the Holy God, it is always the case that to achieve this purpose; this species preferred ways that the amount of human blood on the crimes that can be entered to specify.

An important part of the crime statistics, crimes that constitute the object is imported, that the crimes of battering and reflect the interests of its members or to members of the deterioration. The sentence some of these crimes is based on Islamic Sharia law, which is to come, and from the provisions of some of these crimes is not known. On the crime of domestic members and the loss of their benefits and costs in addition to the blood in cases where the cost-benefit return incomplete or awareness over the amount of diyah is designated for its benefit, it also reviews how to determine the criteria of deterioration or destruction of compensation benefits is not ordain that has a child including these items. On the other hand in some time that the thread has been marked as fixed and appearance reasons associated with significant compromise, including if the amount of the designated benefit for compensation for more than one-third of diyah is the amount of compensation for perfect Muslim man like 
reduced, also pay compensation if the crime is as error and certain deadlines for the return of the prescribed benefit that is to the detriment of criminal against and Johnny or individual that The damage has arrived.

\section{Definition of Crime}

The Arabic word for crime is to pick a fruit from a tree and a sin whose commit will bring penalty in the present world and the world after death (Ibn Asir, 1965). Terminologists believe that the former meaning is the real one and the latter is the virtual meaning of the term for crime (Ibn Hamza, 1988).

Crime is a term in jurisprudence and law, means any damage to the physical integrity of the import is legal, criminal, that individuals such as retribution or retaliation, the word general means a crime. In religious texts, the equivalent word is sin or sending, which means committing sin and do the work of any forbidden or infringement to the property or other thing or lives, including in some sayings (Ibn Abedin, 1978). And consequently in the juridical sources, especially the Hanafi Fiqh, a crime meant committing taboo things when Ihram for Hajj or prohibited tasks within the scope of the shrine, but the original concept of the word in the texts of juridical - actually existed, the term specific to logged bring injury to another i.e., kill or create another injury, fractures and like this in her body. In the concept of crime as well as sayings words used. on this basis, the meaning of the famous crime in any juridical resources, verb or leave the verb that causes physical damage and Johnny come over another and penalty for which it is prescribed (Toosi, 2014).

The so-called crimes to range them and dedicated man, and it did not include physical damage in the import of animals or waste (destroy) animal and also getting damage by animals (Helli, 2000). However, in some broader sources existed in the conceptual and physical integrity beyond harm human and animal to work. For example, in some sources, the damage inflicted by the animal to the property of others, they also read crime (Alamol hoda, 1995 ). Based on this, some authors according to the cited sources in this animal crime, crime is not a crime but a kind of waste have determined them (Oda, 1993), but about creating financial losses, rather than lexical words, most of the crime because the usurpation, steal and waste have been used (Ravas Ghaleji \& Sadegh Ghanibi,1988).

\section{Types of Crime}

1) Intentional Crimes: For being considered as intentional crime, committed in deliberate and must also have the result of intent and with the absence of any one of these two, will not be considered as an intentional crime for. for the realization of criminal behavior in the verb, should deliberate over the will and authority on the desired human, not as a result of the factors (such as madness, ecstasy, coercion, hypnosis) any criminal behavior will not be in a commit; Or of human being what residents have been aware of the infinite (for example, body or animal it deemed to have his TIR Outlook) and he noticed a certain person or action that has not been scheduled, but the bullet had hit him and pervert. In none of these cases, intentional crime committed will not be considered. The recent case of the candidate can be of an article "Islamic Penal Code 290 deduce, that the first evidence for intentional murder case knows that the Commit a crime with the intention of doing something over the individual or individuals gave the Deputy Minister or person or persons that is collected from a non-modal..... "

For being considered as intentional murder or physical injuries, committed, in addition to deliberate on the verb, should plan to create results (i.e. the intent to damage the victim's life or gave away). So, if someone a home, without the knowledge of the people who live in it, and as a result of its inhabitants die, or someone who thought that the default is dead of looming down throw, and he caused the same to be injured or die slat, the Act of intentional murder or commit assaults will not be considered (Sadeghi, 2013). For this reason, in one of the absolutely the decision of the Supreme Court "and intend to deliberate murder and realization condition of proving murder» has been determined.

2) Quasi-Intentional Crimes: In murder or mayhem or mutilation like purposely, knowingly committed and it is when, according to what is in paragraph (a) of article 291," the Islamic penal law, "passed by the year 1392, come," behavioral intention than lunatic committed against the plan but have located or crime, such as it is, and of what is not covered by the definition of the crimes will be intentional, "like it's not going to be that someone, Due to the way that typically is not a crime, and even cause crime, or to disease collaboratively conventional treatment, and even cause the crime on him. " Thus, it is the direction that this action, because of intentional offense to intentionally in the verb, and, due to an error in intention, for the crime of crime is similar to semi-deliberate murder or deliberate error like say.

3) Absolute Error Crimes: In murder or mayhem or mutilation committed and intent», and that if that is not the intention to commit a crime" against the victim on and have no intention of actually gave her on the verb, such as the drop shot to hunt and track individual encounters», or Even someone without intending to hit him, 
causing damage and personal... ". Thus, because the verb is also committed and also has an error going to take offense, once called crime.

\section{Types of Crimes against Benefits of Organs}

There are interests in the human material and of them the forces that in some of the members of the human body is built and they take advantage of a variety of brain and intellect, because hearing loss in the ear and sight in the eye, and so on. Casual crime victim's member of the integrity of the material to be projected on to her injury rules, and sometimes without causing the effect on the victim's member benefits Member material completely or limit human and a member of its full activity (Jafari Langroodi 2008).

The Islamic Penal Code, in article 614-prescribed penalties: "anyone else deliberately maim or cause destruction or rather clownish officials brought the breaking or falling off a member of the permanent members or leading to infection or lack of or a defect of one of the senses or interests or be victim against dementia in cases where is not possible retribution if the action causes disruption in public order and security of society and the preservation be others or commit to the fears of two to five years Prison sentence and will be committed to victim on request against payment of blood money is also to be sentenced. In the event that the incoming waste is not above leading to assaults and the penis hitting a gun or knife and be committed to it three months to one year prison sentence will be». Of the provisions of this article shall apply to the deduction of such a punishment of imprisonment is possible when, during the following steps:

- Firstly occurrence or assaults committed by beat

- Secondly the aforementioned assaults or beating problem led to one of the conditions stipulated in that article

- Thirdly there is the possibility of implementing-retribution

- Fourthly multiply and cause mayhem for disturbing the public order and security of society and the preservation or feared committing crime or others

You need to explain that the phrase "... In cases where retribution is not possible, the emergence in the impossibility arises from the execution of revenge to be passed to a member of the feared and if in the execution of revenge, or losses from crime fears wasted Johnny is feasible, it is not permitted for revenge.

Furthermore, the phrase "no possibility of retribution" also include passed or about to run regardless of revenge to be passed due to possible retribution against victim.

1) Debilitation or broken organ: The purpose of the «mutilation» create shortcomings in the natural appearance or how members and members who usually associated with apparent lesion. Such as tilt, the chorus off ears etc (Shokri, 2002).

After the break a tooth, it does not constitute defects as well as the wobbly tooth to become in effect a deliberate mutilation also beat. Because it is temporarily out of work time and wobbly as a result happened.

Similarly, the realization of the beauty flaws caused the destruction of creation a mere member. For example, the hair may be cut or weld corrosion effect of a conventional assaults on personal virtue and beauty for a fraction of defect, the defect without being a member has created. So any defects shall be deemed to be a member of the destruction of beauty. Of course, in some cases also reflect the beauty flaws caused the members will be together.

2) Debilitation of an Organ: In order to "crash" a member of the members actually means becoming human capabilities and natural member benefit with the survival of members of the disabled, and may even crash a member without causing a change in appearance is a member.

Of course, should consideration though, the term "Member" in the crash article above specifically to absolute but it seems that in order to legislator of this phrase, the apparent members such as hand, foot, neck, ear, nose and the internal organs. Also, this phrase, the rise in the main Member and includes a member of the waste.

Moreover, the work of the members of each Member of a falling human body is naturally practical work and credibility of its members comes on and loss of hearing of the judiciary of a vision of one eye or ear of the judiciary and so on, it is a member of the crash. Therefore, it cannot be said that because the other ear hears with victim against removing into the $\mathrm{s}$. is a member of the finish is not a member.

3) Lack or Mutilation of one of the Senses: Close to understanding and perception and receive is provided by one of the members and the special natural and concentrated on the body. This is apparent in the rise of the senses, senses, and it includes the eyesight powers, mater, taste and touch. 
Create defects in the senses IE mainly healthy appearance is a member but do not have the ability to do normal task. Such as vision defects in or close to debilitation in some close-in smell tastes. Hence, the difference between birth defects and defects close or senses that mutilation is usually associated with the lesion is apparent but apparently healthy members of close defect, but its performance capabilities and pores happen. However, non-apparent defects in the senses, such as memory, imagination and afraid of the judgment of the aforementioned article out.

\section{Punishment of a Crime on an Organ or Its Benefit}

1) Retribution: To find an answer to the question of damages to the benefits and the possibility of retribution, it should be said that:

According to article 387 of Islamic Penal Code, Crime on members, including damage to the interests of the Member or its materiality. So, generally, intentional harm to the interests of the members, including sight, hearing, intellect, memory, speaking, etc., in terms of the conditions prescribed in article $393 \mathrm{~m}$. $\mathrm{m}$. and the items referred to in chapter $\mathrm{v}$ of part II of book IV is liable to qisas (Aghayi Nia, 2014).

The next question is whether the arrival of the crime cannot be independently to the interests of the members of the review? In other words is it possible without having to import its organs commit its benefits go away? For example, whether the person's vision may be the effect of a crime without being wiped from the damaged sign? If the answer is positive, what will be the punishment for committing additional questions? In this section can be raised, such as:

As a result of a fear caused by A, the B loses his power of speaking or loses his common sense without any damage to physical organs of his body, the punishment will be:

According to article 404 of the Islamic Penal Code, If the person is without damaging the other eye, the sight of it, just the sight of the eye can be committed, retribution.

Therefore, the interests of the organ and the Member is not separable materiality and in fact necessary, and health benefit there is a member. With the decline of the members, not benefit. But the result is not a member of the deterioration, deterioration of the supervision of interests and possible without injury is a member benefit, it erodes. In which case the penalty will be committed retribution.

However, the Member shall not damage the interests of qisas to be cordoned off. In such case, due to the lack of the possibility to observe the condition of draws, will not be permitted for qisas.

2) Blood Money: Blood money is paid in the following cases:

a- In the crimes unintentionally members of this crime is intentional or overnight upon error.

b- The intentional crimes where there is retribution for them.

c- The intentional crimes which led to qisas but possible reasons, such as the possibility of qisas committed there is no waste.

d- Victim against the guardians and the amount of diyah or less or more compromise.

In article $614 \mathrm{~m}$. m. as follows from the particular examples of crime on organ refers. This article stipulates that: "anyone who keeps another intention to mayhem that brought the deficiencies or breaking or falling out of the Labor Party from members or want to defect or absence of diabetes educators, or one of the senses, or the interests or dementia in commit crime against the possibility of retribution is not the items that if his action caused disruption in order and safeguard and security of society or email, or he has to fear is two to five years of imprisonment convicted And will he commit crime against the request to pay the diyah is also convicted."

3) Atonement of benefits: If a member is considered to be eligible for that benefit healthy compared to other people. Although it is a member of the weak and the sick. In fact, some of the members have benefits such as its main benefit is that the language of the speaking and its main benefit is that the eye sight. As mentioned, the main interest of the child should not be in the language of the sense of taste, such as child benefit, which has been the main language of the speaking against benefit.

So if a discussion about removing the benefit, the purpose of the main benefit is that it will be paying the full diyeh deserve. It may be between the perpetrator and the existence of the victim against the interests of its members or the lack of it, in the dispute. The law of transition with new actions, the subject is well lit and has stated:

"In cases of dispute between the victim and committed against its destruction or deterioration in benefit, either by a test, confession, judge or promise about the deterioration or destruction of the expert whom, fixed interest, 
in case of realization of the victim against can somehow that prescribed blood money for members, to prove retaliation." If the return is incomplete awareness or interest disputes, victim with a blood oath against proves.

For the repatriation and return of the missing benefit such as wisdom, vision and smell, etc. may not be expert (forensic medicine) given to the return of some interest. According to them the term "one year" (Khoyi, 2001).

The legislator in article 674 of Islamic penal code determine the absolute term brought to speak and did not express it. It seems in all cases according to age, physical condition, type and incoming damage and type of deterioration of benefits, should be given a period of time, and obviously this term must not be unreasonable and long-lasting. Getting the right in a way that doesn't cause awareness against a victim. In any case, seems to be the Max for them will be a year according to the expert and can according to the requirements and other evidence and the situation more or less for a given theorem.

Sometimes it may be a crime which causes the deterioration of one of the interests, spilling and causing the death of the victim against. In this case, the interest of the child in the child's self-confidence and interfere only atonement be confident will claim in this case, it can be said one of two modes. The first case is when the victim against any cause and it is clear that the interest on the declining returns, die. In this case only be truncated or blood awareness benefit claim. The second case, a case that is causing the deterioration of interest is against victim feet (contagion) in this case, the principle of the current conflict and just be confident will claim.

Another point is that whenever a valid through an opportunity which will return incomplete or awareness, the benefit has been determined, a member benefit that vertical it is wiped out. For example, the eye sight it temporarily disappeared from the sponsor is committed only to come out, its benefit is compensation for a temporary decline and its loss if the Member due to the crime someone else committed, second, its full blood member of the sponsor.

Mention this essential point which causes deterioration in the crimes of the interests, the possibility of retribution but the legislator to distinguish the possible intellect is not Mysore. This causes the legislator to in article 677 of Islamic penal "requires a crime which causes dementia or diminish it. However, in case of intentional cause pay diyah and commits is not retribution."

A crime that caused removing of permanent record, the lack of full power during the stool or urine or urine loss frames and cause permanent, deserve a full blood. But removing the power of ejaculation or male or female pregnancy and reproduction or destroying the female or male sexual pleasure.

Eliminating speaking of a person is a child, but if the individual is a part of speaking go away or someone misses some letters (letters of the 32 children) things, towards the speaking split with all the missing child case will be calculated. So if someone cut down some of the language is personal and does not cause loss of the power of pay number of letters (for example, ten characters) and another person another value of his tongue off and caused the loss of the power of pay number of letters (for example, five letter), any person to the ratio of the number of letters that eliminate victim power to pay it, is lost. For example, the first person to the extent of ten-thirty-second person and second full five blood thirty-second full-blood.

Also because the cut or eliminate all the rational language causes the deterioration of voice and speaking. This action causes the two together would be blood money full diyeh of sound and speaking hang and eliminate the language, but if the person is mute, cut and eliminate all the dumb language causes one-third of the full blood.

At the end of this that eliminate or full or temporary defect or other interests of the senses such as touch, sleep, menstrual periods, such as sexually transmitted diseases and also create vibration, thirst, hunger, fear, fainting etc. pursuant.

\section{Conclusion}

If a member is considered to be eligible for that benefit healthy compared to other people. Although it is a member of the weak and the sick. In fact, some of the members have benefits such as its main benefit is that the language of the speaking and its main benefit is that the eye sight. As mentioned, the main interest of the child should not be in the language of the sense of taste, such as child benefit, which has been the main language of the speaking against benefit.

So if a discussion about removing the benefit, the purpose of the main benefit is that it will be paying the full diyeh deserve. It may be between the perpetrator and the existence of the victim against the interests of its members or the lack of it, in the dispute. The law of transition with new actions, the subject is well lit and has stated: 
"In cases of dispute between the victim and committed against its destruction or deterioration in benefit, either by a lab test, confession, judge or promise about the deterioration or destruction of the expert whom, fixed interest, in case of realization of the victim against can somehow oath that prescribed blood money for members, to prove retaliation." If the return is incomplete awareness or interest disputes, victim with a blood oath against proves to be no oath.

For the repatriation and return of the missing benefit such as wisdom, vision and smell, etc. may not be expert (forensic medicine) given to the return of some interest. According to them the term "one year".

Sometimes it may be a crime which causes the deterioration of one of the interests, spilling and causing the death of the victim against. In this case, the interest of the child in the child's self-confidence and interfere only diyah be confident it will be demanding. In this case, it can be said one of two modes. The first case is when the victim against any cause and it is clear that the interest on the declining returns, die. In this case only be truncated or blood awareness benefit claim. The second case, a case that is causing the deterioration of interest is against victim feet (contagion) in this case, the principle of the current conflict and just be confident will claim.

The reasons for the same reasons prove proof of child benefits, child members. In cases of dispute between the victim and committed against its destruction or deterioration in interest, if the lab test and testing, through confession, judge or promise about the deterioration or destruction of the expert whom benefit is not proved, in the case of the realization of the Loth, victim against can somehow oath that ordinated members of prove and if human benefit or return the difference is truncated by the victim against the blood with a fixed and there is no need To oath. In cases where comments have been human interests or incomplete return masters at certain period. If the designated period against victim before the child died is fixed.

The payment of diyah or arsh and commits is not reattributed. "

A crime that caused removing of permanent record, the lack of full power during the stool or urine or urine loss frames and cause permanent, deserve a full blood. But removing the power of ejaculation or male or female pregnancy and reproduction or destroying the female or male sexual pleasure, Hel. Eliminate speaking a person is a child, but if the individual is a part of speaking go away or someone misses some letters (letters of the 32) things, towards the speaking split with all the missing child case will be calculated.

\section{References}

Aghayi Nia, H. (2014). Crimes against Individuals. Mizan Publication,13, 244-247.

Alamol hoda, A. (1995). Al-Intisar. Qom,2, 70-98.

Helli, H. (2000). Montahi ol-Matlab. Al-Shariat. Qom,4,55-61.

Ibn, A. (1965). Al-Nahayat Fi Gharib el-Hadith val-Asar. Published by Tahir Ahmad Zavi and Mahmood Muhammad Tanahi. Cairo,1,113-136.

Ibn, A. (1978). Radol Mohtar alal-Dorrel Mokhtar. Published in Egypt, 72-90.

Ibn, H. (1988). Al-Vasila ela Neil al-Fazilat. Published by: Muhamad Hassoon. Qom ,2, 122-149.

Jafari Langroodi, M. J. (2008). Terminology of Law. Tehran: Ganje Danesh Publication, 19,177-201.

Khoyi, A. (2001). Principles takmelatol Menhaj. Institute for Reviving Works of Imam al-Khoyi,1, 310-320.

Oda, A. (1993). Al-Tashri el-Jenayi el-Islamiye. Beirut. Al-Resale Publication, 4,104-131.

Ravas Ghaleji, M., \& Sadegh Ghanibi, H. (1988). Dictionary of Fiqh. Beirut, 12, 410-438.

Sadeghi, M. M. (2013). Crimes against Individuals (11th ed.). Mizan Publication.

Shokri, R. (2002). Islamic Penal Code in in Modern Legal System. Tehran: Mohajer Publication, 1,614-618.

Toosi, A. (2014). Al-Mabsoot. Maktab Mortazaviye Publication, 1, 34-49.

\section{Copyrights}

Copyright for this article is retained by the author(s), with first publication rights granted to the journal.

This is an open-access article distributed under the terms and conditions of the Creative Commons Attribution license (http://creativecommons.org/licenses/by/4.0/). 